\title{
¿GIRO DECOLONIAL EN EL PATRIMONIO? LA \\ LIBERATION HERITAGE ROUTE COMO ALTERNATIVA \\ POSCOLONIAL DE ACTIVACIÓN PATRIMONIAL ${ }^{1}$
}

\author{
ESTER MASSÓ GUIJARRO \\ Universidad de Granada
}

Dedicado a mis amigos namibios, los freedom fighters y sus descendientes.

\begin{abstract}
Resumen: Considerando el giro decolonial como eje epistemológico clave de revisión sobre patrimonio, se trae a colación como ejemplo discursivo un tipo singular de activación patrimonial, a saber, la Liberation Heritage Route en Sudáfrica, donde se liga el patrimonio, la memoria colectiva, a la lucha de un pueblo por sus derechos, más allá del folclore de corte étnico o nacional. Se tratará de mostrar cómo la Liberation Heritage Route - a modo de estudio de casosupone un ejemplo vivo y notorio precisamente de la apuesta conceptual de este trabajo: es un patrimonio subalterno (o muestra una vía para la subalternización del patrimonio) y, muy especialmente, constituye una forma patente de activación patrimonial holística, donde lo tangible y lo intangible, lo físico y lo simbólico, lo monumental y lo espiritual, se funden en un producto único e indivisible al servicio de la justicia y la dignidad.
\end{abstract}

PALABRAS CLAVE: patrimonio, giro decolonial, Liberation Heritage Route, Sudáfrica, reconciliación.

\section{Decolonial turn on heritage? Liberation Heritage Route as a postcolonial alternative of patrimonial activation}

ABSTRACT: Considering the decolonial turn as a key epistemological axis for troubling heritage, the Liberation Heritage Route in South Africa is brought up as a discursive example, as a unique type of patrimonial activation where heritage (collective memory) is linked to the struggle of a people for their rights, beyond etÚic or national folklore. It will try to show how the Liberation Heritage Route - as a case study - implies a living and notorious example of the very conceptual challenge of this work: it is a subaltern heritage (or shows a pathway for heritage's subalternization) and most especially, it is a patent form of holistic heritage activation, where the tangible and the intangible, the physical and symbolic, monumental and spiritual, come together in a unique and indivisible product at the service of justice and dignity.

KEY WORDS: heritage, decolonial turn, Liberation Heritage Route, South Africa, reconciliation.

1 El presente artículo se ha realizado bajo los auspicios del Proyecto "Derechos humanos y justicia global en el contexto de las migraciones internacionales", del Plan Nacional I+D del Ministerio de Economía y Competitividad (FFI2013-42521-P), y cuyo investigador principal es Juan Carlos Velasco Arroyo. Las principales ideas de este texto fueron presentadas a modo de comunicación oral en el I Congreso Internacional de Antropología AIBR (Antropólogos Iberoamericanos en la Red), "El Ser Humano: culturas, orígenes y destinos", celebrado en Madrid (España) del 7 al 10 de julio 2015. 
1. INTRODUCCIÓN: EL PATRIMONIO EN DISPUTA ${ }^{2}$

«Para Berenguer la patria era pasado y protocolos. Para Dalmau, derechos y futuro» (Sánchez Piñol, 2013, 303).

«[...] lo tangible está en su lugar y lo intangible está en su lugar» (Whitman, 1999, 136).

El patrimonio constituye una noción que ha hecho indudable fortuna, tanto en múltiples disciplinas como en el mundo de la vida y sus distintas esferas sociales, por razones muy diversas. Algunas de ellas, acaso las cruciales, residen en que este concepto confluye enormemente con las melodías filosóficas propias de las tendencias globalizadoras actuales: derechos humanos y colectivos, institucionalización a grandes escalas, garantías de calidad, códigos deontológicos, etc. Supone, en fin, una cristalización de anhelos y símbolos en algo tan concreto, mensurable, universalizable, como la UNESCO o los diversos institutos patrimonialistas nacionales o continentales del patrimonio (Massó Guijarro et al., 2015; Massó Guijarro, 2016).

Cierto que las virtudes de la institucionalización y la globalización del concepto de patrimonio son obvias en múltiples escalas. Sin embargo, tan veraz resulta que su problematicidad epistemológica en el terreno antropológico le ha acompañado desde sus primeros caminos y formulaciones. El patrimonio, como condensación identitaria que implica, en su inexorable vocación de salvaguardia, un estatismo consustancial a cualquier institucionalización, se da de bruces con las teorías más depuradas sobre lo escurridizo, móvil y especular de los mismos conceptos de identidad, cultura, comunidad o tradición (ibíd.).

Para discutir sobre ello, y considerando el giro decolonial (Castro-Gómez y Grosfoguel, 2011) como eje epistemológico clave de revisión sobre patrimonio, se trae a colación como ejemplo discursivo un tipo singular de propuesta patrimonial, a saber, la Liberation Heritage Route $[\mathrm{LHR}]^{3}$ en Sudáfrica. Aún hoy, este país carece de sitios en la lista UNESCO de patrimonio inmaterial y, sin embargo, ha encabezado una propuesta de reconocimiento de sitios patrimoniales (lista tentativa general) confeccionada, por así decir, en torno al concepto mismo de lucha de liberación nacional. Con esta propuesta desafía en buena medida algunos de los elementos más susceptibles de crítica antropológica en el patrimonio, ligándolo esencialmente a la lucha de un pueblo por los derechos, más allá del folclore particular, y la universalización de valores que de ello puede colegirse para el resto de la comunidad internacional.

La propuesta alternativa, memorialista y patrimonialista de un modo radicalmente singular, que supone la LHR, es en esencia un tributo y un homenaje colectivo al «supremo sacrificio por la libertad de los sudafricanos», a través del recuerdo sistemático de «las comunidades, de los eventos, de los lugares, de los iconos y de la grabación de las historias que hacen época, que han tenido un impacto significativo

2 Jugando con el título ya clásico de J. Butler El género en disputa, así como con su aplicación a la discusión sobre el patrimonio, por ejemplo en el título de F. CHOAY, El patrimonio en cuestión. Antología para un combate (2009). Ver también Massó GuIJARro (2015).

3 En lo sucesivo, podrá ser denominada por tales siglas, LHR. Asimismo, se eludirá la cursiva a partir de ahora. 
en la lucha por la liberación de Sudáfrica» (http://www.nhc.org.za/project/liberation-heritage-route/). Así, se liga el patrimonio, la memoria colectiva, a la lucha de un pueblo por sus derechos, más allá del folclore de corte étnico o nacional. No es ningún folclore particular lo que Sudáfrica ha postulado en la UNESCO como patrimonio sino su lucha misma, su liberación. ¿Puede la liberación ser patrimonio? ¿Desafía esto a los elementos más susceptibles de crítica antropológica en el patrimonio, defendiendo en realidad una visión sobre el mismo que describiremos como decolonial, poscolonial y combativa, un patrimonio al servicio de la justicia, necesariamente híbrido y estratégico?

El abordaje de la LHR servirá para discutir sobre una posible forma o enfoque patrimonial con especial sentido en las sociedades poscoloniales, un discurso sobre la sociedad tradicional y el patrimonio en la contemporaneidad que salve los escollos descritos sobre el patrimonio desde la antropología (cf. González Alcantud, 2012; Prats, 2004). Asumimos así un patrimonio no tanto inmaterial cuanto holístico y plural, siempre en tránsito de lo objetual a la síntesis entre el objeto, la acción y el ritual.

El artículo se desarrolla en dos partes fundamentales. En la primera parte se aborda el concepto de patrimonio de un modo analítico y especulativo, con el objetivo de perfilar mi apuesta conceptual sobre una idea de patrimonio subalterno (la subalternización de patrimonio como elemento vivo, de los pueblos) y, esencialmente, holístico (una suerte de híbrido epistemológico que supere la dicotomía, de raíz platónica, entre patrimonio inmaterial y material). Las dos citas con que comienza este artículo aluden, respectivamente, precisamente a estas dos apuestas: de un lado, una subalternización del patrimonio, donde éste sea «derechos y futuro» (frente a la visión de corte más clásico y elitista en la que era "pasado y protocolos»); de otro lado, una superación del dualismo clásico occidental entre mente (intangible) y cuerpo (tangible). Ambos ejercicios epistemológicos encarnan además una hermenéutica puramente decolonial y/o de descolonización, en tanto que implican transcender un pensamiento jerárquico —elites frente a subalternos - sobre el mundo, en el que prepondera la raíz occidental frente a cualquier otra. Tales envites teóricos cobran sentido en un marco reflexión general sobre la justicia en la globalización (y ya que la LHR, como veremos, en esencia es un ejercicio memorialista de justicia) y la necesidad de realizar un abordaje decolonial sobre el patrimonio - dicho de otro modo, de descolonizarlo conceptual y empíricamente-.

En la segunda parte del artículo se tratará de mostrar cómo la LHR —a modo de estudio de caso- supone un ejemplo vivo y notorio precisamente de la apuesta conceptual anterior: es un patrimonio subalterno (o muestra una vía para la subalternización del patrimonio) y, muy especialmente, constituye una forma patente de activación patrimonial holística, donde lo tangible y lo intangible, lo físico y lo simbólico, lo monumental y lo espiritual, se funden en un producto único e indivisible (como acaso todo lo real, en verdad). Por último, en las conclusiones se reflexionará de modo conjunto sobre ello en el marco general de la decolonialidad, intentando apuntarse a algunas posibles prospectivas de trabajo venidero. 


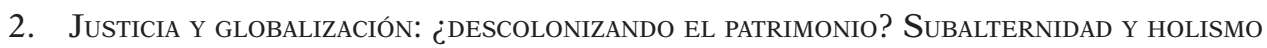

«The project engages with silent voices» (AA. VV., 2013, 7-84).

La intensa movilidad humana del mundo contemporáneo ha supuesto una transformación profunda en la concepción y la aplicación de la justicia. Seguimos aquí propuestas en la estela del sesgo globalista o cosmopolita (Beitz, Barry, Pogge, Nussbaum, Fraser, Sen, Risse, entre otros, tal y como lo trabajan por ejemplo Velasco Arroyo, 2013). El elemento fundamental de esta teoría cosmopolita de la justicia se encontraría una noción integral de los derechos humanos, en línea con el art. 28 de la Declaración Universal de los Derechos Humanos: «Toda persona tiene derecho a que se establezca un orden social e internacional en el que los derechos y libertades proclamados en esta Declaración se hagan plenamente efectivos»; en línea también con el informe sobre desarrollo humano del PNUD (2009).

Por otro lado, las corrientes analíticas más novedosas sobre patrimonio coinciden en abordarlo como arena de escenificación y expresión de conflictos; esto significa su asunción en sus condiciones sociales de existencia y como una «formación discursiva» (Foucault, 1992) sobre el pasado que supone su uso presente, siempre en el juego dialéctico del olvido y el recuerdo, el silencio y la memoria (el «past presencing» y la «memory complex» acuñados por MacDonald, 2012; Harrison, 2012) (del Mármol Cartañá, 2015). El pasado es en este sentido un concepto maleable, proclive a la escenificación del conflicto (también del consenso o la victoria pasada o incluso la derrota pasada devenida en catalizador), y que permite hablar metafóricamente del pasado con usos simbólicos muy efectivos. Existe siempre una polifonía de voces que construyen las voces del pasado; siempre hay voceros con más o menos credibilidad y legitimidad sobre los pasados, distintas retóricas de poder que reconfiguran las relaciones entre agentes en localidades específicas; el patrimonio como un ámbito de negociación entre poderes diversos (Appadurai, 1981; Yelvington, 2002). Es también analizado como régimen del cuidado (regimen of care; Harrison, 2015), y muestra su evolución en la diversificación de la diferencia de discursos de conservación, restauración, salvaguarda o protección. Nielsen (2011), por su parte, analiza la ideología cultural de la UNESCO (sobre su aplicación al patrimonio) en relación a cuestiones de reconocimiento y redistribución, lo que supone en realidad su análisis sobre temas básicos de las teorías contemporáneas sobre la justicia global.

Dejando a un lado las disputas académicas sobre la naturaleza del patrimonio, es un hecho incontestable que, a efectos prácticos, para muchos pueblos y comunidades la declaración de la UNESCO ha supuesto la posibilidad del uso del patrimonio como bandera simbólica (Pastor, 2015) ligada de un modo muy particular a la justicia; ello sobre todo desde su Convención de 1973 y, muy especialmente, desde la del patrimonio inmaterial (2003), que a fin de cuentas trata de cualquier tipo de práctica cultural (hay de facto casi una superposición terminológica entre cultura y patrimonio inmaterial, si analizamos las definiciones de ambas en la UNESCO y los diccionarios de antropología; algunos hablan de metonimia; Pereiro Pérez, 2012).

\footnotetext{
4 Cf. También AA. VV., 2007.
} 
El patrimonio vivo de los grupos indígenas como forma de capital social reconocido nos permite hablar, en cierto modo, de un patrimonio decolonial, subalterno (jugando con la concepción gramsciana de la hegemonía y la subalternidad) (Gramsci, 2000; Modonesi, 2012); o un uso subalterno del concepto "patrimonio». Los hasta ahora "sin voz», los subalternos, desde la reclamación de las epistemologías silenciadas, vindican precisamente que sea expuesto, activado, sacado a la luz, dignificado por el pincel internacional UNESCO, lo que antes fue pasto de los gusanos coloniales. En contextos poscoloniales potentes, como América Latina o África, el discurso del patrimonio casa magníficamente con los estudios poscoloniales y el giro decolonial (Sousa Santos, 2015; Fanon, 2009; Mignolo, 2010; etc.).

La herencia patrimonial que se reclama es aborigen, la que había en el origen y fue pisoteada; se sublima aquella forma de violencia que Fanon $(1961,1964)$ creía liberadora durante la lucha anticolonial, ahora en la forma simbólica y no violenta de re-inventar un pasado esencialmente subalterno confiriéndole la relevancia de patrimonio de la humanidad (sello/marca de calidad). En realidad, lo que sucede en casos como el la LHR sudafricana es una activación patrimonial de corte decolonial. Así, pienso que muy bien podemos hablar sin ambages hoy de una subalternidad del patrimonio, o de un uso combativo, dignificante y subversivo del orden hegemónico a través del concepto de patrimonio como arma —cognitiva-ideológica- El patrimonio devendría método descolonizador, vehiculador de apropiaciones contrahegemónicas y una dignificación de esos «mundos alternativos que no se pueden nombrar en lenguas coloniales», esas heterodoxias cognitivas que nombra Sousa Santos (2015).

La dignificación autoafirmativa que suponen los reconocimientos patrimoniales para los "pueblos del sur», expresa también esa dignificación simbólica a través del concepto de universalidad: si hasta ahora la universalidad había sido, primariamente, occidental o europea (oxímoron), reconocer algo como de valor universal supone algo grande. «Los idiomas deberían ser universales, como la música, el amor o las grandes ideas»(Ana, 2007, 332). Aquí matiza Marcos Ana, ningún experto en patrimonio y acaso precisamente por ello, con esa honda frescura suya, bella y casi aniñada en ocasiones, con la limpieza de la mirada infantil: que hay en lo hermoso un necesario matiz de universalidad: que algo tan valioso o tan bello no puede ser solo de uno.

Precisamente en torno a la división entre patrimonio material e inmaterial, como apunté más arriba, supondrá también la LHR un ejemplo desafiante (entre tantos posibles) de dicha dicotomía necesariamente artificial, de corte platónico y arraigada en fin en un dualismo que ha atravesado la historia del pensamiento occidental: la división neta entre lo físico y lo inmaterial, lo tangible y lo intangible, la mente y el cuerpo, el cuerpo y el alma, que Platón (el flanco griego) inmortalizó, Agustín de Hipona (el flanco judeocristiano) sacralizó y Descartes (el flanco ilustrado) selló en la filosofía racionalista occidental (Estrada Díaz, 1996), coagulando una ficción epistemológica que se arrastra hasta nuestros días.

Frente a ello, lo que propongo aquí es que, a la par que se descolonice el concepto de patrimonio (en aras de su uso al servicio de la justicia y que acabe siendo, en fin, un patrimonio subalterno), se discuta y problematice también la división entre patrimonio material e inmaterial, proponiéndose un concepto híbrido de patrimonio holístico, $\mathrm{u}$ holismo en el patrimonio. La LHR constituye una activación 
patrimonial propuesta a la lista general de monumentos (no material) y, sin embargo, está al servicio de una cultura de justicia, con lo cual podría ser muy bien también enclavado en la lista de patrimonio inmaterial. Lo que finalmente se pone de manifiesto no es tanto que la activación que supone la LHR podría estar en ambas listas, cuanto la inconsistencia misma de dicha división conceptual reflejada en aquellas listas.

A ello nos referimos con la idea de la subalternidad y el holismo patrimonialistas, un concepto de patrimonio subalterno (vivo, del pueblo, descolonizado) y, por ende, holístico, que supere la diferenciación entre inmaterial y material. El ejemplo a continuación pretende ser una muestra de todo ello.

3. El CONCEPTO DE PATRIMONIO DECOLONIAL COMO HERRAMIENTA ANALÍTICO-POLÍTICA: La Liberation Heritage Route en Sudáfrica

«In the new South Africa, a national heritage complex has been constituted out of narratives of great leaders' epic lives and the triumph of the human spirit, and from stories of a rainbow nation that has experienced reconciliation. While new biographic museums and memorials present the nation's 'long walk to freedom', apartheid's constructs of race and ethnicity were morphed into a post-apartheid discourse of diversity and a new nation comprising 'many cultures'» (Rassool, 2012, 1).

\subsection{Orígenes, sentido y algunas revisiones: ¿el patrimonio revisitado?}

«The LHR reflects the supreme sacrifice for the freedom of South Africans. It is about the recognition of people, communities, events, places, icons and recording of epoch-making stories which had a significant impact on the South African struggle for liberation» (http://www.nhc.org.za/project/liberation-heritage-route/).

La LHR (AA. VV., 2007; AA. VV., 2009) constituye un proyecto de activación patrimonial llevado a cabo por el National Heritage Council (NHC) de Sudáfrica y remitido a UNESCO en el año 2009, cuyo principal fin es realizar la crónica de un singular viaje por y de la liberación nacional sudafricana. En la actualidad la propuesta se halla en la lista tentativa. La iniciativa forma parte de un programa mucho más amplio denominado «Roads to Independence in Africa: The African Liberation Heritage», coordinado por UNESCO apoyado por la Unión Africana (Bialostocka, 2013).

El objetivo central del mismo es asegurar un testamento perdurable de la lucha de liberación tan duramente ganada, a través de establecer vínculos entre las narrativas y las huellas de dicha lucha a través de los diferentes pero interconectados sitios (patrimoniales) emblemáticos a través del país. Han sido tenidos en cuenta, para esta selección, los siguientes elementos, cuestiones o plataformas sociales: guerras de despojo o desposesión, lucha de liberación en general y movimientos democráticos de masas, intelectuales africanos pioneros, masacres y asesinatos históricos, juicios, movimientos de mujeres, jóvenes, estudiantes y sindicales, organizaciones religiosas y deporte y formaciones culturales en general.

La LHR se define como la suma de los siguientes objetivos: 1. Patrimonio común de valores mundiales compartidos (derechos Humanos, libertad, democracia, 
etc.); 2. Promoción del diálogo entre pueblos y culturas; 3. Desarrollar y promover cultura de paz; 4. Contribuir a la memoria del mundo; 5. Generación de datos y bases de datos para crear conciencia. En suma, se da un uso del patrimonio para objetivos sociales, que transcienden con mucho la mera acepción esteticista y elitista del patrimonio, y que apuntan a conceptos y facticidades como (según el propio expediente oficial): (a) el perdón, (b) la justicia transicional, (c) la construcción nacional, (d) la reconciliación y (e) la generación de nuevas identidades híbridas.

Los estudios críticos de patrimonio (critical heritage studies ${ }^{5}$ ) en Sudáfrica constituyen un campo crucial de análisis e investigación. Algunas de las principales inquietudes y grandes temáticas son el análisis de determinados enclaves académicos mismos, como la Universidad de Ciudad del Cabo, como lugares patrimoniales en sí mismos, a través de su propia representación institucional y el estilo propio que ha desarrollado. Proliferan estudios sobre las distintas políticas en torno a los restos humanos y repatriación de los mismos, la dialéctica «olvido-recuerdo» sobre el apartheid, así como las variadas políticas de la memoria; en general, cómo el patrimonio y la memoria, en un enclave etnonacional tan particular y complejo como Sudáfrica, suponen un terreno nutrido de contestaciones sobre cultura, identidad e historia.

Algunas otras líneas fundamentales de trabajo contemporáneo al respecto en la academia sudafricana consisten en analizar el laboratorio de nueva formación y transformación patrimonial en el país, con especial énfasis en las nuevas museologías y prácticas patrimonialistas que han emergido para trascender las teleologías de la raza y el nacionalismo (Rassool, 2012). Todo ello es parte de redes de trabajo e historia pública novedosas, a través de los abordajes emergentes de los critical heritage studies, que pretenden trascender las relaciones de conocimiento jerárquicas, que cuestionan el clásico concepto de experticia (working of expertise) y trabajan con nociones como la recuperación (recovery) (ibíd.). Todo ello, por supuesto, posee su correspondiente reflejo en los currículos escolares en diversas escalas (Rassool, 2012). El objetivo principal es el poder democratizador de la historia oral y cómo a través de la recuperación de las narraciones en primera persona de la ciudadanía sudafricana se obtiene algo más que una "supplementary source ${ }^{6}$ » para reconstruir la historia reciente (cf. también Deacon, 2012). Otros análisis destacados en relación a estas cuestiones son los de Roux (2012) sobre la historia pública y las memorias ordinarias (patrimonio urbano en Eastern Cape); los de Witz (2012a, 2012b), sobre museología contemporánea en Sudáfrica como patrimonio post-apartheid; o los de Murray, Shepherd y Hall (2007) sobre las relaciones urbanas entre espacio, memoria e identidad en las ciudades contemporáneas tras el apartheid.

Constituyen enfoques sumamente ricos y complejos ya que involucran, por necesidad, campos de estudio muy variados, desde la arqueología incluso o la antropología física (por ejemplo, por cuanto tiene que ver con respecto a cuestiones de exhumaciones por la memoria histórica) hasta, precisamente, las disputas más actuales en cuanto a estudios críticos de patrimonio. Resultan especialmente

\footnotetext{
5 Un ejemplo significativo lo encontramos en la siguiente agenda académica: http://www.africanstudies.uct.ac.za/content/critical-issues-heritage-studies. Resulta muy significativo el título de uno de los cursos de posgrado, por ejemplo: «Critical Issues on Heritage Studies».

6 «In spite of their commitment to the democratising power of oral history, for many South African social historians, it constituted only a supplementary source» (RAssool, 2012, 3).
} 
oportunos para el florecimiento de estos enfoques críticos estos lugares donde las memorias son controvertidas, se han visto especialmente golpeados por lo que supone la disputa identitaria; por el rostro más amargo y violento de las gramáticas de subjetividad más complejas (la intensa multiculturalidad sudafricana que generó el apartheid, ante la incapacidad de asumir las diferencias como bondades). Estos lugares donde el perdón no ha sido retórica religiosa sino pura necesidad de sobrevivencia, donde conceptos como ubuntu ${ }^{7}$ encarnan un auténtico capital social que está deviniendo "patrimonio de la humanidad» en tantos sentidos... estos lugares nos permiten pensar y repensarnos como humanos, como especie cultural capaz de la mayor barbarie, la más compleja y, también, de la virtud más sostenible.

Como no podía ser de otro modo, la academia (sudafricana e internacional) se ha ocupado especialmente en los últimos años de analizar y repensar la iniciativa patrimonial tan singular que supone la LHR. Bialostocka (2013) plantea la LHR como una propuesta que pretende, de un lado, preservar el legado de la lucha de liberación sudafricana (el long walk to freedom que Mandela inmortalizó con esta misma denominación en sus memorias homónimas) y, de otro lado, operar como posible motor económico a través del turismo patrimonial; así las cosas, se pregunta si la iniciativa constituye, más que un camino hacia el futuro, una reminiscencia de un pasado doloroso. Los análisis académicos sobre la LHR se han orientado a aventurar prospectivas sobre sus beneficios (socioculturales y económicos) a largo plazo, con énfasis especial en los principios del desarrollo sostenible (Snowball y Courtney, 2010); dicho de otro modo: han indagado sobre cuáles son las mejores prácticas para equilibrar la necesidad de conservación del patrimonio (tangible e intangible) que constituye la esencia de la LHR, con el objetivo de usarlo como producto, en definitiva, turístico (ibíd.).

Bialostocka $(2013,2014)$ destaca también el aspecto del valor de la LHR como herramienta didáctica, incluso para los propios sudafricanos (no solo para el turismo internacional): "More often than visiting cultural/heritage sites or taking part in cultural events, South Africans choose eating out or shopping [...] It is mostly highly educated South Africans who find interest in heritage» (Bialostocka, 2013, 5-6). En función, precisamente, de hechos como este, el gobierno sudafricano está desarrollando estrategias para activar nichos de mercado como el turismo rural y patrimonial que contribuyan a paliar las pobres cifras de turismo cultural en el país. Así, la promoción de la LHR debería combinarse con campañas educativas

\footnotetext{
7 «Ubuntu» constituye un concepto tan proteico y complejo que sería motivo de un artículo (o una tesis) independiente. Aporto al menos una línea al respecto, como mínima aclaración. Nelson Mandela, en su discurso durante la recepción del Premio Nobel, refirió el concepto «ubuntu» (de raíces zulúes-xhosa) como la cosmovisión orgánica o filosofía, puramente africana, por la que se entiende, se reconoce, se asume que herir a cualquier persona significa herir al resto. Esta noción, que fue recuperada como retórica humanista especialmente durante el proceso de reconciliación tras el apartheid, es clásicamente traducida como «humanidad entre otros» y resulta análoga a los valores estructurales de los derechos humanos y el humanismo en general. "Ubuntu» considera, de modo intrínseco, que la identidad se funda estructuralmente en la alteridad, de modo que cualquier afección ajena influye en lo propio, derivándose un concepto de bien o de virtud necesariamente colectivo, cooperativo y sinérgico (al modo como lo entienden Kropotkin, Margulis, Maturana o Varela), frente al juego suma-cero. El ubuntu es clave hoy en los estudios sobre paz y conflictos desde perspectivas poscoloniales (cf. Massó Guljarro, 2009).
} 
destinadas a que la ciudadanía sudafricana (re)descubra su propio patrimonio (ibíd.), siendo algunas de las propuestas prácticas al respecto la promoción de viajes escolares (con la preparación de paquetes educativos para escuelas, materiales promocionales para los maestros con líneas de trabajo sobre historia), donde se presente de modo accesible y atractivo a los más jóvenes la historia de liberación y el respeto a los mayores, el desarrollo de una serie de festivales con motivos históricos en cada provincia ligados a la LHR, con especial énfasis en la conservación de los sitios; o la creación de un ticket único para la LHR al completo, así como precios especiales para entradas familiares y escolares (ibíd.).

\subsection{Los lugares emblemáticos: del veldt ${ }^{8}$ al cementerio, de la universidad a la cárcel}

«Though Cultural Routes have resulted from both peaceful and hostile encounters, they present a number of shared dimensions which transcend their original functions, offering an exceptional setting for a culture of peace based on ties of shared history as well as the tolerance, respect, and appreciation for cultural diversity that characterize the communities involved» (ICOMOS, en Bialostocka, 2013, 6).

Inspirada en una propuesta anterior análoga en Australia (en la lista tentativa de este Estado), la LHR propone trece lugares concretos de reconocimiento patrimonial, ubicados en los siguientes estados, provincias o regiones del país: Gauteng, Limpopo, Mpumalanga, Free State, Northern Cape, North West, Eastern Cape, Western Cape y las provincias de KwaZulu Natal.

Los principales sitios escogidos son, pues, trece (Bialostocka, 2013), trece enclaves que oscilan desde lugares de saber, como universidades, hasta cementerios conmemorativos y lugares de horror donde se perpetraran grandes masacres, como el terrible ejemplo de Sharpville, donde fueran fusilados estudiantes y niños de escuela. Así, la condición y carácter de estos trece altos en el camino son tremendamente variados, con signos tanto positivos (lugares donde sucedieron hechos buenos) como negativos (lugares de masacres); la memoria posee sobre ellos un doble significado: en algunos casos, se debe recordar estos lugares para no olvidar la fundamental dignidad colectiva que supusieron; en otros casos, lo que no se debe olvidar es la maldad que llegó a perpetrarse, precisamente para no repetir la historia.

Se ofrece a continuación un relato minucioso de los trece lugares y su descripción según el expediente oficial recogido en UNESCO (http://www.nhc.org.za/pro ject/liberation-heritage-route/):

1) La Isla de Robben (Robben Island ${ }^{9}$ ): señalado en primer lugar, probablemente su hermosa silueta frente a las Table Mountain fue la imagen simbólica más emblemática de Sudáfrica durante décadas, junto con el rostro dibujado de su preso más insigne, Nelson Mandela. Esta pequeña isla, a siete kilómetros de las costas de Ciudad del Cabo, fue durante décadas la

8 Término tradicional de origen afrikáans para nombrar las praderas de Sudáfrica.

9 La significación de Robben Island es tal que supone un enclave patrimonial de primer orden en sí mismo, y como tal se la está tratando y activando. Constituye una interesante experiencia que puede consultarse en la dinámica web http://www.robben-island.org.za/, donde se accede tanto a un recorrido virtual por la isla como a entrevistas orales con algunos de los líderes encarcelados y, por supuesto, información sobre los tickets y paquetes turísticos para visitarla en barco, etc. 
cárcel de trabajos forzados donde por antonomasia se confinaba a los presos políticos (freedom fighters, combatientes por la libertad) en la Sudáfrica del apartheid, muchos de los que ahora son líderes políticos. En esta isla Nelson Mandela cumplió buena parte de sus veintiocho años de encarcelamiento.

2) La Universidad de Fort Hare ${ }^{10}$ : ubicada en Alice (provincia de Eastern Cape), fue la primera «Universidad negra», famosa por constituir el centro académico más importante de desarrollo y aprendizaje de la mayoría de líderes políticos - tanto sudafricanos como de otras procedencias africanas - durante décadas, como por ejemplo Nelson Mandela, Seretse Khama de Botswana, Robert Mugabe de Zimbabue o Charles Njonjo de Kenya, entre otros.

3) La Walter Sisulu Square of Dedication ${ }^{11}$ (Kliptown, Soweto, un área urbana situada a 24 kilómetros al suroeste de Johannesburgo en la provincia de Gauteng, y el gueto negro por antonomasia durante el apartheid): esta plaza constituye un enclave simbólico por la memoria de Walter Sisulu (una de las grandes figuras de la resistencia en el ANC (African National Congress), junto a Mandela, Tambo, Nkomo o Mda) en particular, y por todos los combatientes de la liberación, en general, en tanto que fue allí donde la Carta de Libertad del ANC fue presentada en el Congreso del Pueblo en 1955.

4) Diversos lugares relacionados con Nelson Mandela («Nelson Mandela Sites»), como su pueblo y hogar de la infancia en Qunu (Transkei), su casa en Soweto o la "Mandela House» ${ }^{12}$, que compartió con Winnie Mandela y es considerado hoy un lugar patrimonial crucial asociado con la historia de liberación.

5) La Casa de Robert Mangaliso Sobukwe: ubicada en Kimberly, capital de la provincial de Northern Cape. Sobukwe fundó y presidió el Congreso Panafricano (PAC). En 1959 el PAC, escindido del ANC el año anterior, orquestó la famosa campaña contra los pases, tal vez la más popular de todas (Benson, 1986, 19). En este hogar fue mantenido en arresto domiciliario Sobukwe a partir de 1969, cuando fue liberado de Robben Island tras tres años de prisión por incitación a la violencia a raíz de la mencionada campaña no violenta de desobediencia civil.

6) La Casa de Steve Buntu Biko ${ }^{13}$ y la Clínica Zanempilo ${ }^{14}$ : son lugares ubicados en King William's Town, en la provincia de Eastern Cape, y asociados en la lucha de liberación especialmente liderada por Steve Biko. La Zanempilo Clinic fue fundada para atender especialmente a personas negras, dada la inequidad en la atención médica durante el apartheid en función del color, y en la casa de Biko este fue confinado a arresto domiciliario. Biko, un joven estudiante de medicina, fue la fuerza principal del Movimiento de Conciencia Negro que abogaba por la liberación de los negros, el orgullo de la raza y la oposición no violenta. En 1977, en una de las ocasiones en que burló el confinamiento para

10 Su sitio web oficial actual es www.ufh.ac.za.

11 La correspondiente web oficial de esta activación patrimonial es http://www.waltersisulusquare.co.za/.

12 Puede consultarse más información en http://www.mandelahouse.co.za/.

13 Cf. http://sbf.org.za/biko-heritage-trail.php para mayor información; corresponde al sitio web de la Fundación Steve Biko.

14 Cf. http://sbf.org.za/zanempilo-clinic.php para mayor información. 
acudir a una reunión política, fue detenido durante el camino y oficialmente declarado muerto por «enfermedad» en prisión a los tres días, a causa de los golpes recibidos y la falta de atención médica correspondiente. La Sociedad Médica de Sudáfrica lo denunció y tras estos incidentes el escenario sudafricano cambió radicalmente. Una nueva generación de jóvenes negros estaba dispuesta a luchar bajo el lema de «liberación antes que educación».

7) La Colina de la Constitución ${ }^{15}$ (Constitution Hill): ubicada en Braamfontein, un barrio central hoy de Johannesburgo, constituye un museo vivo (living museum) a causa de su compleja historia que se remonta a 1892, cuando el Old Fort fue construido bajo la Zuid Afrikaanse Republiek. Funcionó como prisión (a excepción del breve período de la guerra de Sudáfrica entre 1899 y 1902), siendo conocida por las células de aislamiento y por albergar módulos especiales para mujeres presas. Era también el lugar donde se confinaba a los acusados en espera de juicio, como sucedió con Nelson Mandela y otros nueve líderes antiapartheid durante el proceso de Rivonia.

8) Museo del Jefe Albert Luthuli ${ }^{16}$ (Chief Albert Luthuli Museum): hogar del que fuera primer Premio Nobel de la Paz africano (1960), ubicado en la pequeña ciudad de KwaDukuza, previamente conocida como Groutvilled, al noreste de Durban. Luthuli presidió el ANC entre 1952 y 1967, y también resultó acusado de alta traición en 1956 junto a otros 155 detenidos (Mandela, 1964: 164, 165).

9) La estatua conmemorativa de Hector Pieterson (o Hector Zolile Pitso) (Hector Pieterson Memorial): este muchacho, nacido y muerto en Soweto (19631976) se convirtió en el ícono de los levantamientos de este distrito cuando el reportero gráfico Sam Nzima tomó una fotografía suya agonizante en brazos de un compañero, Mbuyisa Makhubo, y acompañado por su hermana Antoinette. Dicha fotografía dio la vuelta al mundo: Hector, asesinado a la edad de 12 años, el 16 de junio de 1976, cuando la policía abrió fuego en contra de unos estudiantes que protestaban; niños en pantalones cortos que daban saltos. Este día fue un símbolo de la resistencia a la brutalidad del gobierno del apartheid y actualmente se le conoce como el Día Nacional de la Juventud en Sudáfrica.

10) Sharpeville: se conmemora en el término municipal de Sharpeville, situado en el Transvaal meridional, la matanza que tuvo lugar a unos $8 \mathrm{~km}$ de la ciudad de Vereeniging. El 21 de marzo de 1960 la policía abrió fuego contra una manifestación antigubernamental en esta localidad, acto que tuvo como consecuencia la muerte de 69 personas negras, entre ellas mujeres y niños, y otras 180 heridas. El 30 de marzo de 1960 el gobierno declaró el estado de emergencia y fueron detenidas 11.727 personas. El ANC y el PAC fueron prohibidos y sus miembros obligados a pasar a la clandestinidad o a exiliarse. Desde ese momento ambas formaciones abandonaron la tradicional estrategia de protesta no violenta e iniciaron una incesante lucha armada. A la matanza de Sharpeville sucedió una oleada de protestas en todo el mundo, incluida la condena de las Naciones Unidas (ONU).

15 Puede consultar más información sobre la activación patrimonial al respecto en https:// www.constitutionhill.org.za/

16 El sitio web oficial es http://www.luthulimuseum.org.za/. 
11) La Casa de Sol Plaatjie (y el Sol Plaatjie Museum): ubicada en Kimberley (Nothern Cape), fue el hogar del político, escritor y periodista especialmente notable durante la lucha contra el apartheid, donde escribió obras como Mhudi. Plaatje fue miembro fundador y primer Secretario General del South African Native National Congress (SANNC), que devino en el imbatible ANC. Su tumba en el cementerio de West End Kimberley fue también declarado patrimonio en la provincia.

12) La Granja Liliesleaf ${ }^{17}$ : ubicada el barrio residencial de Rivonia, distrito de Johannesburgo, constituye un lugar histórico del movimiento de liberación, ya que un grupo nutrido del liderazgo del ANC (Nelson Mandela, Denis Goldberg, Ahmed Kathrada, Andrew Mlangeni, Govan Mbeki, Walter Sisulu, Elias Motsoaledi y Raymond Mhlaba) fueron allí arrestados y confinados, tras haber usado estos espacios para encuentros clandestinos del ANC; constituyó así el centro neurálgico del movimiento de liberación.

13) El Cementerio Avalon ${ }^{18}$ : ubicado, como tantos otros lugares patrimoniales, en Soweto, es uno de los cementerios más grandes de Sudáfrica y en él se hallan enterrados gran cantidad de combatientes por la libertad. Fue inaugurado en 1972, durante el apogeo del apartheid, como un camposanto exclusivamente para negros. Más de 300.000 personas están enterradas en sus cerca de dos kilómetros cuadrados).

Se ofrece a continuación un mapa con las ubicaciones aproximadas de los trece lugares:

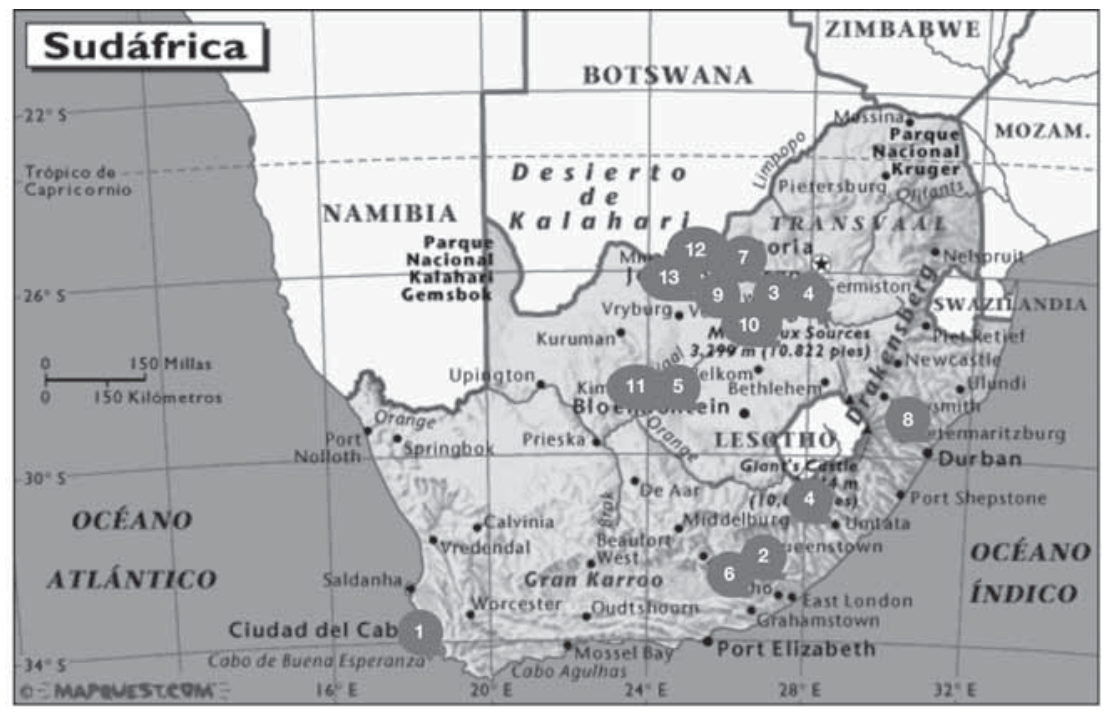

[Fuente: elaboración propia (mapa base: http://www.lospaises.com.ar/africa/sudafrica.htm) (las ubicaciones son aproximadas)].

17 El sitio web oficial de esta iniciativa patrimonial es http://www.liliesleaf.co.za/.

18 En el siguiente sitio web puede consultarse más información al respecto: http://www.jo burg.org.za/index.php?option=com_content\&id=7319:heroes-buried-at-avalon\&Itemid $=266$ 
Por razones históricas obvias, puede comprobarse cómo una gran mayoría de sitios se concentra en las áreas de Johannesburgo y Pretoria, aunque, en general, bien es cierto que los lugares se reparten también por puntos diversos de la geografía sudafricana. Así, como se apuntaba al inicio, los lugares escogidos son bien diversos, tanto en su carácter, sus constituciones monumentales o arquitectónicas, como en sus funciones simbólicas y también, por qué no, su posible capitalización monetaria. Sobre ello reflexiona Bialostocka (2014) que, a pesar de que la iniciativa parece constituir el ejemplo perfecto de proyecto de conservación patrimonial económicamente viable, no todos los sitios escogidos pueden devenir empresas productivas en lo económico (con independencia de lo bien preservadas o publicitadas que se hallen). Esta autora defiende que la pura lógica mercantil (por la cual estos «lugares inaprovechables» deberían ser abandonados por improductivos) no debería nunca ensombrecer el actual valor cultural de tales vestigios históricos ${ }^{19}$.

\subsection{Análisis: la sublimación colectiva del dolor, el patrimonio como reconciliación, el perdón como patrimonio}

«because of you

this country no longer lies

between us but within

it breathes becalmed

after being wounded

in its wondrous throat

in the cradle of my skull

it sings, it ignites

my tongue, my inner ear, the cavity of heart

shudders towards the outline

new in soft intimate clicks and gutturals

of my soul the retina learns to expand

daily because by a thousand stories

I was scorched

a new skin.

I am changed forever. I want to say:

forgive me

forgive me

forgive me

You whom I have wronged take me with you» (Krog, 199820).

La poeta y periodista sudafricana-afrikáner Antjie Krog dedica este poema «for every victim who had an Afrikaner surname on her lips». Se ha optado por incluirlo íntegro en tanto que resulta inspirador al respecto de las ideas básicas que aquí se desea transmitir: ilustra, a través de esa forma de patrimonio (¿inmaterial?) que

19 Con todo, no es en absoluto el objetivo de este trabajo un análisis de corte economicista y/o de perfil productivo sobre la iniciativa LHR; así, no se ha incluido datos económicos sobre el expediente de la UNESCO, por ejemplo, que la persona interesada podrá consultar en el lugar oficial correspondiente.

20 Este fragmento es la sexta parte (f) del largo poema «Country of grief and grace» (la presentación en línea carece de paginación). 
constituye la escritura (más aún, la autonarración poética, casi como etnografía íntima en casos como el de Krog), la contradicción afectiva que subyace a la nación arco iris, al ubuntu, tras la experiencia de apartheid en Sudáfrica. Sugiere tambíen cómo el perdón emergió en la nueva Sudáfrica como un cemento social básico y cómo, en iniciativas como la LHR, la base que opera como hilo conductor en el patrimonio es la reconciliación nacional: la restauración de la dignidad a través del reconocimiento de tantas personas que fueron masacradas y simplemente olvidadas; como canta Kroj, en un país que nunca más se yerga entre nosotros sino con nosotros.

Su voz sobre la «nueva piel» es más que una metáfora epidérmica en torno a la política de colores en el apartheid, acaso la narración real más organizada y terrible en torno a la inequidad fenotípica a lo largo de la historia de la humanidad. No: cuando Kroj habla de la «nueva piel», habla de la nueva Sudáfrica multicolor en su pura esencia, de su constitución, de sus políticas reparativas, de cómo la ciudadanía sudafricana desde 1994 es, inexorablemente, mestiza. Así, por todo ello, consideramos apropiado defender una suerte de sublimación colectiva del dolor a través del patrimonio que es la LHR; más aún, del perdón colectivo erigido en forma de patrimonio, como la cosmovisión o ideología ubuntu enseña.

La LHR, por cuanto se ha ido mentando, emerge como una forma de patrimonio o activación patrimonial descentralizada, autoapropiada por los protagonistas culturales con finalidades éticas, que transcienden con mucho lo meramente folclórico o esencialista cultural. Si el patrimonio es en realidad el epítome que cada cultura desea singularizar de sí misma, mostrar, exhibir... y también comercializar, potenciar, instrumentalizar, capitalizar... globalizar, lo que Sudáfrica desea ensalzar como «su epítome» es su misma lucha de liberación, una lucha a través de la cual se acuñó la conciencia de pueblo colectiva que es Sudáfrica hoy: necesariamente plural, híbrida, multicultural y aún en proceso de reconciliación. Sudáfrica ofrece al mundo lo que la ha configurado como lo que es hoy, la nación arco iris. Todo ello, además, con un concepto autóctono (vernáculo) clave, como es el de ubuntu.

El patrimonio es la institucionalización (turística a menudo, simbólica siempre) de la identidad; supone la coagulación de unos símbolos identitarios, por motivos diversos. Se populariza e inevitablemente, con ello, también se pervierte, se banaliza, se comercia... todo eso es también popularizar. La historia o la memoria, el pasado en definitiva, no se desvirtúa (o no siempre) con la patrimonialización sino más bien lo contrario: se virtualiza, en su doble sentido de ficción y de ponderación o hagiografía (llenarse de virtudes). En esa medida, cuando el discurso o la activación patrimoniales operan en tal sentido, lo que se patrimonializa parece ser precisamente la resistencia (se folcloriza la resistencia), una resistencia en virtud, finalmente, de la justicia. Este patrimonio «de otra manera», o esta otra manera de ser del patrimonio, supone un desplazamiento semántico acaso, o complejización/ actualización del concepto, una vindicación para su uso más real, menos formalista y más humanitario.

La activación patrimonial operaría, pues, como instrumento social de reflexión, participación e integración. La patrimonialización trascendería el mercado, en tanto que implicaría, en primer lugar, una reflexividad interna como proceso; en segundo lugar, una reinvención sincrética, acaso rehabilitación, de ciertos valores o prácticas que fueran negados (silenciados, oprimidos) y que hoy puedan 
ser reclamados como memoria histórica. La activación patrimonial se revela como forma de justicia reparativa, como contemplamos notoriamente en la LHR de Sudáfrica.

Siguiendo la expresión de Soldino Nicolás (2004: 37) sobre el patrimonio como la "acción ciudadana rescatada», los «sentimientos y sensaciones cotidianos en cada ciudad y en cada pueblo» o esas "cuestiones liberadas desde lo más hondo», ante la «frustración e impotencia» frente a las amenazas contra la identidad y la cultural, la activación patrimonial que supone la LHR en Sudáfrica, es, absolutamente, un patrimonio decolonial. Dicho de otro modo, constituye un «dispositivo memorial intencional» (Choay, 2009: V) al servicio de esa otra memoria, o acaso mejor esa otra forma de hacer memoria, que supone el giro decolonial: una memoria también selectiva (eso siempre, imposible una memoria holística), pero esta vez escorada del lado de la mayoría, del pueblo, del tercer estado, del tercer mundo, de las mujeres y los menores y las minorías en el seno de mayorías hegemónicas, y las mayorías hasta ahora no hegemónicas. Una memoria, en definitiva, ideológicamente poscolonial y/o decolonial o descolonizada.

\section{REFLEXIONES FINALES: EL CUENTO DECOLONIAL, EL CUENTO LIBERADO}

«As a battle for universal values such as freedom and human rights, the liberation struggle that Africa experienced in the twentieth century is a common narrative and a shared heritage of the continent» (Bialostocka, 2013, 1).

«¿Cómo puedo olvidar aquel tiempo, Rafael?

Tú sabes que no enseña sino el hermano,

Y en esa hora no solo aquello me enseñaste,

Sino la rectitud de mi destino.

Y cuando una vez más llegó la sangre a España

Defendí el patrimonio del pueblo que era el mío»

(Pablo Neruda ${ }^{21}$, citado en Ana, 2007, 311 [el énfasis es mío]).

Estos versos muestran la idea de patrimonio que se ha querido aquí reflejar o debatir. Un patrimonio que no puede olvidarse —cómo puedo olvidar aquel tiempo- porque es de sangre y es del pueblo, un patrimonio que necesariamente se transmite a través de lo fraternal, lo transmite el igual, el hermano (tú sabes que no enseña sino el hermano), y no un grupo de expertos desde su palestra. Eso sería, entre otras cosas, un patrimonio decolonial, o un concepto de patrimonio reacuñado desde el giro decolonial.

Si la cultura significa, según la UNESCO, un patrimonio colectivo, esa colección de mundos desde los que se habla y se recuerda; si cada vez más los estudios sobre patrimonio hablan del patrimonio de la gente (Soldino Nicolás, 2004; Delgado, 2006); si el patrimonio significa un proceso intangible de producción de sentido, una reconstrucción o reconversión de algo obsoleto y disfrutado como «algo nuevo», entonces podemos hablar sin ambages del patrimonio como un instrumento

21 Poema de Neruda dedicado a Rafael Alberti en su cumpleaños, el 16 de diciembre de 1948, cuando el vate chileno huía hacia Argentina, cruzando a caballo la cordillera de los Andes. 
de lucha colectiva por el reconocimiento. Patrimonio, pues, como un concepto que puede y debe ser tratado según un enfoque decolonial. Como bien precisa Sousa Santos, los pueblos del sur son aún hoy no tanto sujetos de derechos humanos cuanto objetos de discurso de derechos humanos y, en esa medida, los reconocimientos patrimoniales suponen una asunción de protagonismo.

En realidad, todo patrimonio considerado legítimo hoy día es, necesariamente, un patrimonio poscolonial y, más aún, descolonizado, en esa búsqueda de paisajes cognitivos más amplios que proponen autores como Sousa Santos (2015); «ampliar la conversación del mundo", en esa sociología de las ausencias y sociología de las emergencias; el patrimonio, así concebido, supone la amplificación simbólica de lo que no ha sido contado. Esto no supone ignorar los estudios críticos sobre patrimonio (cf. Coombe y Weiss, 2015; Mármol, Morell y Chalcraft, 2015) sino, antes bien, asumir sus críticas para proponer distintos modos de enfocar este concepto multiuso, por así decir, usando también planteamientos y utillaje epistemológico de otros lugares de conocimiento 22 .

Como decíamos más arriba, la LHR forma parte de un proyecto y una aspiración más amplios, que trascienden Sudáfrica como nación e incluso África austral como región. Se trata, como señala Bialostocka en la cita que encabeza estas conclusiones, de recuperar y poner en valor una narrativa común en África de lucha de liberación, de batalla de valores universales como la libertad y los derechos humanos, como patrimonio compartido en el continente; una memoria colectiva pergeñada y nacida de la experiencia colonial y la necesaria descolonización, de la «memoria de la resistencia contra la dominación extranjera» («memory of resistance against foreign rule», ibíd.). Ello constituye por tanto una forma de patrimonio y memoria decoloniales, esto es: transidas por la inexorable memoria del pasado colonial, que aúna identidades y sirve de elemento coagulante de una autocomprensión contemporánea, necesariamente híbrida, compleja (etnonacional, pluriétnica), pero que se sabe en el mismo camino ${ }^{23}$. Todo ello contribuye, además, a perfilar la condición agonística de toda política realmente democrática en Sudáfrica, la inexorable condición agonal de las políticas identitarias en la nación arco iris; el agonismo (frente al antagonismo), ese «espíritu de lucha» (según el DRAE) que tan bien ha descrito Mouffe (1993) como elemento intrínseco de la democracia.

Dice Saramago en su Viaje a Portugal que «El viajero viajó por su país. Esto significa que viajó por dentro de sí mismo, por la cultura que lo formó y está formando, significa que fue, durante muchas semanas, un espejo que refleja imágenes exteriores, una vidriera transparente que luces y sombras atravesaron, una placa sensible que registró, en tránsito y proceso, las impresiones, las voces, el murmullo infinito de un pueblo» (Saramago, 2004, 5). Siguiendo esta magnífica descripción de ese viaje de la identidad que es, también, el patrimonio, tengo para mí que éste

22 En un trabajo bastante anterior (Massó GuIJARRo, 2006) argumenté sobre los posibles réditos culturales y políticos que podría producir cierto empleo o instrumentalización del patrimonio inmaterial para salvaguardar o ponderar flujos de capital social y modos de identidad.

${ }_{23}$ En el caso de la vecina Namibia (hasta los años noventa, parte de Sudáfrica), la identidad namibia se conforma precisamente en virtud de esa "sangre derramada" por un mismo objetivo, por encima de lenguas y diversidades, y que arracima la complejidad en la «umbrela national identity» (Massó Guijarro, 2011a y 2011b). 
no debiera ser sino, a fin de cuentas, el cuento que una cultura se cuenta sobre sí misma, ese murmullo infinito de un pueblo (Massó et al, 2015); ese espejo que refleja fuera y dentro, porque qué cosa es, si no, la identidad, sino un baile constante entre las percepciones de todo aquello que es otro (alteridad) y todo aquello que es propio (autorreconocimiento). Lo que un poeta llama «cuento», la ciencia social llama autonarración o etnografía ${ }^{24}$; ese cuento como patrimonio que se propone aquí, y que se ha rastreado para el caso de Sudáfrica, es un cuento liberado, un cuento que se pretende decolonial o descolonizado, mostrando esa forma posible de patrimonio, alejada de experticias y elites, y más próxima a lo subalterno y a una expresión holística (tangible e intangible a la vez) de la cultura humana que aspira a la justicia.

\section{Bibliografía}

AA. VV. (2007), Roads to independence: the African Liberation Heritage Programme. Dar es Salaam: UNESCO Office Dar es Salaam. En línea: http://unesdoc.unesco.org/ images/0015/001540/154025eo.pdf

AA. VV. (2013), «Documentation of Sites, Heroes and Heroines of the Liberation Struggle in the Gert Sibande District Municipality». Mpumalanga Province, District Chapter of the National Liberation Heritage Route (NLHR).

Ana, M. (2007), Decidme cómo es un árbol. Memoria de la prisión y de la vida. Barcelona: Tabla Rasa.

Appadurai, A. (1981), «The past as a scarce resource». Man, New Series, vol. 16, n 2, pp. $201-$ 219.

BARBER, L. (2012), «New geographies of heritage: (re) scaling frames and (re) situating mobile policy inventions». Congreso Internacional de la Association of Critical Heritage Studies: «The Re/theorisation of Heritage Studies», Gotemburgo, 5-8 junio: http://critical heritagestudies.org/sites/default/files/1367357_p420-barber-new-geographies.pdf

Benson, M. (1988), Nelson Mandela, biografía. Madrid: IEPALA.

Bialostocka, O. (2013), "Liberation Heritage Route: Reminiscent of the Painful Past or a Road to the Future?». Policy Brief, Africa Institute or South Africa, 100.

Bialostocka, O. (2014), «Using the past to build the future: a critical review of the Liberation Heritage Route (LHR) Project of South Africa». Africa Insight, vol. 44, no 2, pp. 94-107.

Castro-Gómez, S. y Grosfoguel, R. (Coords.) (2011), El giro decolonial. Reflexiones para una diversidad epistémica más allá del capitalismo global. Madrid: Siglo del Hombre Editores.

Соомве, R. J. y Weiss, L. M. (2015), Neoliberalism, Heritage Regimes, and Cultural Rights. En L. Meskel, (Ed.), Global heritage: a reader (pp. 43-69). НовокеN N. J.: Wiley Blackell.

Снолу, F. (2009), Le Patrimoine en questions. Anthologie pour un combat. Paris: Seuil.

Deacon, H. (2012), Narrowing the gap Between critical Heritage studies and critical heritage praxis in Africa. Congreso Internacional de la Association of Critical Heritage Studies: «The Re/theorisation of Heritage Studies», (conferencia inaugural), Gotemburgo, 5-8 junio.

Delgado, M. (2006), "Sobre antropología, patrimonio y espacio público». Revista Austral de Ciencias Sociales, $\mathrm{n}^{\circ} 10$, pp. 49-66.

Estrada Díaz, J. A. (1996), Dios en las tradiciones filosóficas. Madrid: Trotta.

Fanon, F. (1961), Los condenados de la tierra. México: Fondo de Cultura Económica.

${ }^{24}$ Cf. FAssin (2015) para un encomio de la etnografía hoy como escritura de los pueblos y la ciudadanía. 
Fanon, F. (1964), Por la revolución africana (Escritos políticos). México: Colección Popular Tiempo Presente.

Fanon, F. (2009), Piel negra, máscaras blancas. Madrid: Akal.

FASsin, D. (2015), «Noticias del terreno. Una defensa e ilustración de la etnografía». Conferencia inaugural en el I Congreso Internacional de Antropología AIBR «El ser humano: culturas, orígenes y destinos». Madrid, 7-10 julio.

Foucault, M. (1992), Microfísica del poder. Madrid: Endymión.

González Alcantud, J. A. (2012), El malestar en la cultura patrimonial. La otra memoria global. Madrid: Anthropos.

Gramsci, A. (2000), Cuadernos de la cárcel. México: Universidad Autónoma de Puebla.

HARRISON, R. (2013), «Forgetting to remember, remembering to forget: late modern heritage practices, sustainability and the 'crisis' of accumulation of the past». International Journal of Heritage Studies, vol. 19, $\mathrm{n}^{\circ} 6$.

Houston, G.; Mati, S.; Seabe, D.; Peires, J.; WebB, D.; Dumisa, S.; Sausi, K. et al. (2013), «The Liberation Struggle and Liberation Heritage Sites in South Africa». Informe del Democracy, Governance, and Service Delivery (DGSD) Human Sciences Research Council, noviembre 2013.

KiRshenBLATT-GimBlett, B. (2004), «Intangible heritage as metacultural production». Museum International, vol. 221-222, $\mathrm{n}^{\circ}$ 56, pp. 52-65.

KROG, A. (1998), «Country of grief and grace». En línea: http://www.poetryinternationalweb. net/pi/site/poem/item/5392/auto/COUNTRY-OF-GRIEF-AND-GRACE

MacDonald, S. (2012), «Presencing Europe's Past». En U. Kockel, M. Nic Craith, J.Frykman y S. Macdonald (Coords.), A Companion to the Anthropology of Europe. Oxford: Blackwell Publishing Ltd.

Mandela, N. R. (2005), Un camino nada fácil hacia la libertad. España: Zanzíbar.

Mármol Cartañá, C. (2015), Para algo que era nuestro, ahora es de la Humanidad. Patrimonio como arena de expresión del conflicto. IV Jornadas de la Asociación Valenciana de Antropología Patrimonio, Memoria y Conflicto, Valencia, 24-25 abril 2015.

Mármol, C.; Morell, M. y Chalcraft, J. (2015), The making of heritage. Seduction and disenchantment. Nueva York: Routledge.

Massó Guijarro, E. (2006), «La identidad cultural como patrimonio inmaterial: relaciones dialécticas con el desarrollo». THEORIA, n 15/1, pp. 89-99.

Massó Guijarro, E. (2009), «Ubuntu, satyagraha y derechos humanos. Policentrismo de fuentes en la (cultura de) paz». Iztapalapa, vol. 30, nº 66, pp. 185-202.

Massó GuiJarro, E. (2011a), La franja de Caprivi en el Estado de Namibia: ¿etnicidad, regionalismo o proyecto nacionalizante?. Berlín: Editorial Académica Española.

Massó Guijarro, E. (2011b), La franja de Caprivi en el Estado de Namibia: ¿etnicidad, regionalismo o proyecto nacionalizante? ANEXOS. Berlín: Editorial Académica Española.

Massó Guijarro, E. (2016), "La Plaza de las Pasiegas en Granada: historia (s) de nodrizas. Memorias orales de ayer y hoy". Dilemata. Revista Internacional de Éticas Aplicadas. En prensa.

Massó Guijarro, E.; Mondragón Valero, P. y Santángelo Lázaro, A. (2015), "Patrimonio, antropología y caza: experimentos pedagógicos en un aula de la UGR". Revista de Antropología Experimental, n ${ }^{\circ} 15$, pp. 65-78.

Massó Guijarro, E.; Mondragón Valero, P. y Santángelo Lázaro, A. (2015), «Patrimonio, antropología y caza: experimentos pedagógicos en un aula de la UGR». Revista de Antropología Experimental, no 15, pp. 65-78.

Mignolo, W. (2010), Desobediencia epistémica. Buenos Aires: Ediciones del Signo.

Modonesi, M. (2012), Subalternidad. México: Instituto de Investigaciones Sociales, Universidad Nacional Autónoma de México.

Mouffe, C. (1993), El retorno de lo político. Comunidad, ciudadanía, pluralismo, democracia radical. Barcelona: Paidós. 
Murray, N.; Shepherd, N. y Hall, M. (Coords.) (2007), Desire Lines; Space, memory and identity in the post-apartheid city. Oxford: Routledge.

NIELSEN, B. (2011), «UNESCO and the 'right' kind of culture: bureaucratic production and articulation». Critique of Anthropology, n ${ }^{\circ} 31$, pp. 273-292.

PAstor, M. J. (2015), Patrimonio: memoria y resistencia. IV Jornadas de la Asociación Valenciana de Antropología Patrimonio, memoria y conflicto, Valencia, 24-25 abril.

Pereiro Pérez, X. (2012), «La concepción del patrimonio etnoantropológico en Galicia: visiones legales y prácticas institucionales». Revista Andaluza de Antropología, $\mathrm{n}^{\circ} 2$ (sin paginación en versión electrónica).

Prats, L. (2004), Antropología y patrimonio. Barcelona: Ariel Antropología.

Rassool, C. (2012), «Critical heritage practice and the empire of the museum: new challenges of repatriation and restitution in Southern Africa». Congreso Internacional de la Association of Critical Heritage Studies: «The Re/theorisation of Heritage Studies», Gotemburgo, 5-8 junio: http://www.gu.se/digitalAssets/1366/1366981_p072ciraj-rassool-abstract.pdf

Roux, N. (2012), «Public history and ordinary memories: urban heritage in the Eastern Cape, South Africa». Congreso Internacional de la Association of Critical Heritage Studies: "The Re/theorisation of Heritage Studies», Gotemburgo, 5-8 junio: http://critical heritagestudies.org/sites/default/files/1367299_p344-roux-public-history.p

Sánchez Piñol, A. (2013), Victus. Barcelona 1714. Barcelona: La Campana.

SARAmago, J. (2004), Viaje a Portugal. Barcelona: Santillana.

Snowball, J. D. y Courtney, S. (2010), "Cultural heritage routes in South Africa: Effective tools for heritage conservation and local economic development?». Development Southern Africa, Special Issue: _ Local economic development in Africa, vol. 27, no 4, pp. 563-576.

Sousa SANTos, B. (2015), «Epistemologías del Sur: democratizar, descolonizar, desmercantilizar el saber y la sociedad». Conferencia pronunciada el 26/04/2015, Universidad de Granada.

Velasco Arroyo, J. C. (2013), «Justicia global y el gobierno de las migraciones internacionales». Revista de Estudios Sociales, $\mathrm{n}^{\circ}$ 47, pp. 107-117.

Whitman, W. (1999), Hojas de hierba. Madrid: Austral.

WiTz, L. (2012a), «From Write Your Own History to heritage formation in South Africa after apartheid: Producing oral histories as intangible». Congreso Internacional de la Association of Critical Heritage Studies: «The Re/theorisation of Heritage Studies», Gotemburgo, 5-8 junio.

WiTz, L. (2012b), «Making museums as heritage in post-apartheid South Africa». Congreso Internacional de la Association of Critical Heritage Studies: "The Re/theorisation of Heritage Studies», Gotemburgo, 5-8 junio. Yelvington, K. (2002). «History, memory and identity: a programmatic prolegomenon». Critical Anthropology, vol. 22, no 3, pp. 227-256.

Departamento de Antropología Social, Facultad de Filosofía y Letras,

Ester Massó Guijarro Universidad de Granada; Campus Cartuja s/n ester@ugr.es

[Artículo aprobado para publicación en diciembre de 2015] 
